\title{
What do Biphasic Flow Experiments Reveal On the Variability of Exposure on Alluvial Fans and Which Implications for Risk Assessment Result From This?
}

\section{Hector Diaz}

Universidad Austral de Chile Facultad de Ciencias

Bruno Mazzorana ( $\sim$ bruno.mazzorana@uach.cl)

Universidad Austral de Chile Facultad de Ciencias https://orcid.org/0000-0003-1218-4495

\section{Bernhard Gems}

University of Innsbruck Faculty of Civil Engineering: Universitat Innsbruck Fakultat fur Technische Wissenschaften

\section{Ivan Rojas}

Universidad Austral de Chile - Campus Isla Teja

\section{Nicole Santibañez}

Universidad Austral de Chile Facultad de Ciencias

\section{Pablo Iribarren}

Universidad Austral de Chile Facultad de Ciencias

\section{Mario Pino}

Universidad Austral de Chile Facultad de Ciencias

Andres Iroumé

Universidad Austral de Chile - Campus Isla Teja

\section{Research Article}

Keywords: Alluvial fan, Fluvial Hazard, Flood risk, Exposure, Experimental model, Process similarity

Posted Date: September 27th, 2021

DOl: https://doi.org/10.21203/rs.3.rs-869837/v1

License: (9) (1) This work is licensed under a Creative Commons Attribution 4.0 International License. Read Full License 
Version of Record: A version of this preprint was published at Natural Hazards on January 5th, 2022. See the published version at https://doi.org/10.1007/s11069-021-05169-8. 


\section{Abstract}

Autogenic processes, such as sudden avulsions, unexpected channel migrations and backfilling phenomena, can considerably alter the propagation of sediment-laden flows on alluvial fans. Once the initial and boundary conditions of the hazard scenario with a given return period are determined, the delineation of the associated exposed areas is based on one numerical, essentially deterministic, process simulation, which may not adequately reflect the underlying process variability. By following a 'similarity-

of-process concept' we generated sediment-laden flows on an experimental alluvial fan. Thereby, we considered an alluvial fan model layout with a curved guiding channel and featuring a convex shape. As loading conditions, we defined a reference, an increased and a reduced level for the released water volume and the predisposed solid fraction. Further, we imposed two different stream power regimes and executed, for each factor combination, eight experimental runs. The associated exposure areas were recorded by video and were mapped in a GIS. We then analyzed exposure data and derived exposure probability maps superposing the footprints of the eight repetitions generated by each experimental loading condition. The patterns of exposure associated with specific loading conditions showed a noticeable variability due to the main effect of the total event volume, the solid fraction and the interactions between them and with the imposed stream power in the feeding channel. Our research highlights that a probabilistic notion of exposure in risk assessment and mitigation needs to be considered. Further, a major challenge consists in adapting numerical codes to better mirror the stochastics of process propagation for more reliable flood hazard and risk assessments.

\section{Introduction}

Since time immemorial alluvial fans have been privileged settlement areas, despite being prone to fluvial hazards (Okunishi et al. 2001; Mazzorana et al. 2020). They are depositional landforms widespread in almost all climatic environments of the world (Antronico et al. 2015) interfering with the sediment transfer in mountainous watersheds as temporary storage areas. Commonly, these depositional forms evolve at the outlet of narrow and steep valleys, due to the disparity between the upstream and the downstream sediment transport capacity (Bull 1977; Clarke 2015). Starting from a topographic apex, they normally spread in a radiating pattern (Bowman, 2019), forming conical bodies with concave longitudinal and convex cross profiles (Drew 1873; Galloway et al. 1996; Clevis et al. 2003).

On these landforms, flood hazards may hit in an often rapid and almost unforeseeable manner (Blair \& McPherson 1994; National Research Council 1996) and flood control is a challenging social and engineering endeavour (Mazzorana and Fuchs 2010a). Despite conspicuous investments in structural protection, flood risk management agencies failed to provide a safe environment for settlement development and the expanding economy (Mazzorana et al. 2014). On the contrary, vicious risk cycles frequently unfolded whenever the construction of additional protective elements induced a strong perception of protection and unleashed further land occupation (MacDonald et al. 2000; Mazzorana et al. 2018). 
A plethora of geomorphic forms and signatures demonstrates that on alluvial fans, sediment-laden flow propagation is complex and is determined by allogenic processes which interact with the pre-existing morphologies giving rise to autogenic phenomena that may render process propagation even more unpredictable (Blair \& McPherson 2009; Ruiz-Villanueva et al. 2019, Mokarram et al. 2021). As stated by Clarke (2015), only acquiring profound knowledge of the alluvial fan morphology and analysing process evolution in different spatial and temporal settings may lead to a better understanding of alluvial fan evolution and response. Thereby multiple contingencies have to be considered. The geomorphic evolution trajectories strongly depend on allogenic controls (i.e. forces external to the fan system such as tectonics, volcanism, climate, base-level rise, glacier lake outburst floods and the catchment characteristics) and autogenic controls which Clarke (2015) describes as internally derived thresholds within the fan system or process responses arising, ceteris paribus, from internal feedbacks (Muto et al. 2007).

In many regions of the European Alps, significant efforts have been undertaken to provide hazard maps as essential tools for enhanced spatial planning, aiming at achieving effective risk mitigation. Improving flood risk management decisions crucially depend on the accuracy and reliability of the outputs of employed hazard models (Alexander 2000; Kienholz et al. 2004; Fuchs 2009; Bubeck et al. 2016). Such models, however, are imperfect abstractions of reality and precise data to determine both their initial and boundary conditions as well as to set relevant model parameters are rarely if ever available. Data errors and modelling uncertainties may frequently interact and modelling outputs may be inherently imprecise. It is frequently asserted that recurring to a historical record of extreme events with a thoroughly assessed hydrological context, carefully documented silent witnesses (i.e. watermarks, levees, and deposition lobes) and gathered flow data and video-recorded flow patterns would be necessary to calibrate the employed models until modelling outputs satisfactorily match the extent and the propagation patterns of the observed events (Santo et al. 2015). The calibrated model would then be used with increased confidence to deterministically simulate flood hazards with different initial and boundary conditions (i.e. corresponding to prescribed return periods) to provide for a complete hazard assessment according to the adopted regional and national standards. But what if rather than being deterministic, process propagation on unconfined landforms such as alluvial fans naturally exhibited an inherently stochastic process behaviour due to the aforementioned process interactions? Wouldn't this mean that if nature were to repeat virtually the same initial and boundary conditions (i.e. in terms of flow rates, sediment transport rates, etc.) process propagation would unfold differently and potentially in an unexpected way? Wouldn't this also mean that calibrating models to match specific outcomes would subtly introduce additional biases?

These questions are crucial to hazard as well as to risk assessment. On rigorous scrutiny, however, these questions are not unambiguous. The complexity of nature as an experimental device is unimaginable and the repetition of the same initial and boundary conditions for a hazard event is impossible. The problem resides in our limited capability in accurately and precisely detecting the uniqueness of each unfolding process. Due to this limitation, we may overlook that events with macroscopically indiscernible boundary conditions are distinguishable in at least one small, albeit relevant, undetected detail (i.e. slightly different composition of the flow mixture, slightly perturbed flow rates etc.) and may unfold 
differently. Analogous arguments hold for the initial conditions, which do change over time (i.e. vegetation cover and patchiness, local surface roughness, etc.) and, as such, further contribute to the uniqueness of each unfolding event. But, viewed through the blurred modelling lens, these different conditions would appear indiscernible. Due to the profound implications for our ability as a society to proactively adapt and enhance our resilience to the impacts of flood hazards in mountainous environments, quantifying the variability of hazard exposure due to sediment-laden flows on unconfined landforms (i.e. alluvial fans), triggered by a set of practically indiscernible loading conditions, is imperative.

Experimental alluvial fan models offer the possibility to explore the ramifications of this fundamental problem and have been largely adopted also by hydro-geomorphologists (Hooke 1968; D'Agostino et al. 2010; Clarke 2015; Feng et al. 2019). Important advances could be achieved in determining the primary factors influencing alluvial fan dynamics, such as slope (Hooke 1968; Guerit et al. 2014), avulsion (Bryant et al. 1995; Reitz and Jerolmack 2012), autogenic processes (Muto et al. 2007; Van Dijk et al. 2012), and risk (Davies et al. 2003).

In our research we follow a 'similarity of process concept' (Hooke, 1968) and, rather than scaling a realworld prototype, we regard the physical alluvial fan model as a prototype in its own right.

It's worth disclosing at the outset that this experimental approach is not exempt from important limitations. In particular, scaling problems need to be addressed, as they can often distort certain flow processes and the resulting morphologies. For this reason, the obtained experimental findings are not meant to be directly transferred to any particular field setting (Paola et al. 2009; Sturm et al. 2018a, b). They can be discussed, however, in light of their general implications for hazard management since they highlight potential sources of uncertainty that may affect process propagation and exposure profoundly.

In the quest for new insights on this research topic we define the following objectives of our experimental research:

(i) Retracing the exposed areas on the alluvial fan surface and determining the associated variability by experimentally establishing indiscernible conditions for the repeated generation of sediment-laden flows;

(ii) Exploring the dependence of the variability of exposure from the applied loading conditions (i.e. a reference, an increased and a reduced level for the released water volume and the predisposed solid fraction as well as two stream power regimes);

(iii)Deducing the important implications for hazard and risk assessment that can be drawn from the obtained experimental results.

The remainder of the paper is organized as follows. Section 2 is dedicated to the employed materials and methods. Herein, we describe the adopted experimental design and the employed procedure for exposure detection. Then, in Sect. 3, we present the obtained results. The implications of these results for hazard and risk assessment are discussed in Sect. 4. To underline the practical relevance of these implications 
we refer the reader also to a well-documented study area that comprises the Blanco River basin and the Chaitén city area (i.e. active river channel, urbanized floodplain area and river fan-delta system). A compound event triggered by the 2008 Chaitén volcano eruption took place, which changed the curved river setting profoundly and severely hit extended residential sectors of the city. The distributary dynamics on the inhabited fan-delta was particularly complex and completely unexpected (Basso-Báez et al. 2020). This section contains also the main concluding remarks.

\section{Materials And Methods 2.1. Background}

Conjointly used fieldwork methods and computational approaches are essential and complement each other in attempting to accurately mirror morphodynamic processes on an alluvial fan, but, as argued above, they may only provide a partial representation of its evolution (Clarke et al. 2010; Harvey 2012). It might also be challenging, relying on them alone, to identify and quantitatively assess all intervening key factors and components. Hence, employing the experimental approach could be, despite the limitations and drawbacks outlined earlier, a promising way to complement the traditional approaches in effectively attaining the research objectives formulated in the introduction section. For this, our research strategy is pillared on the following four conceptual elements:

i) Quantification of exposure and qualitative assessment of the underlying distributary dynamics and related phenomena, concerning the analysis of the generated system response, coherently with the defined research objectives adopting the 'similarity-of-process-concept' concept (Clarke 2015);

ii) Use of a basic experimental setup, which features, despite its simplicity, the required parameters, allowing the definition and measurement of the system loading and response parameters;

iii) Modular system layout, for agile prototyping and rapid execution of the experimental runs (Mazzorana et 2017);

iv) Repetition of experimentally indiscernible loading conditions as a basis for the potential emergence of the variability of the exposure patterns on the alluvial fan surface.

We remark that the experimental setup used in this study does not allow reproducing the whole set of phenomena occurring in nature because the adopted alluvial fan features a non-erodible surface, whose elevation vertically limits channel incision on the previously deposited lobes. In addition, observed process dynamics are only macroscopically similar within the context of the similitude-by-process approach, which means that physical processes occurring in nature may only partially be reproduced. Anyway, despite the presence of the non-erodible surface, understanding the peculiarities of distributary processes, where channel incision below the original fan surface is not to be expected, is not precluded. Moreover, this setting is useful for capturing channelization and self-confining flows on previously deposited material. 
According to the stated purposes of this study, in this section, we present the experimental model setup and the accomplished experimental program. We describe the analytic steps to assess the exposure resulting from the propagation of the sediment-laden flow on the alluvial fan surface for each experimental run. Then, we outline how to delineate the exposed areas and calculate exposure probabilities in a spatially explicit way considering all exposure footprints associated with the same indiscernible loading conditions. Finally, we describe the ANOVA method (Dean et al. 2017) to test if exposure is differing significantly in relation to the applied loading conditions (i.e. total discharge volume, stream power and solid fraction) and their interactions.

\subsection{Experimental model}

The experimental model set-up consists of three movable components: the alluvial fan equipped with a curved dextral guiding channel, the feeding channel, and the supply tank. The dimensions of the model are reported in Fig. 1. A water container with a maximum capacity of $1.5 \mathrm{I}$ releases the water at each repetition by manually handling a valve that can take three different positions: closed, half-opened, fully opened. The released water is conveyed along a feeding channel towards the alluvial fan apex. The entire structure of the feeding channel is made of PVC and the channel bed is covered by PEVA. The middle segment has a vertical step followed by a horizontal tract; this simulates the area where the stored sediment can be entrained by water and the sediment-laden flow is initiated. The downstream segment is connected to the alluvial fan.

The structure of the fan model is made of PVC and the fan surface has an area of is $21.41 \mathrm{dm}^{2}$ and is composed of PEVA, providing some surface roughness to the potential unconfined flow areas. The curved guiding channel represents a typical torrent control measure employed on these landforms in the attempt to safely convey the sediment-laden flows to the receiving watercourse. The alluvial fan is surrounded by a containment rubber pool to prevent water and sediment to leave the system. The tap regulating the flow of water from the tank is set $42.0 \mathrm{~cm}$ above the base of the system and it is opened to establish a medium or a full stream power regime, by controlling the release time of the liquid water volume. A camera, model GoPro Hero Session with a photo resolution of 8 megapixels and a video resolution of $1920 \times 1080$ pixel at $60 \mathrm{fps}$, is installed $0.9 \mathrm{~m}$ orthogonally above the model base to record all the conducted experiments.

The sediment material is quartz, with a known density of $2.58 \mathrm{~g} / \mathrm{cm}^{3}$, and its grain size distribution is limited to the narrow range of b-axis diameter class between 1 and $2 \mathrm{~mm}(\mu=1.53 \mathrm{~mm}, \sigma=0.17 \mathrm{~mm})$.

\subsection{Experimental program}

The experiments are conducted at specific combinations of the released total discharge volume $(V)$ and the predisposed solid fraction $(s)$. Standard total discharge volume $\left(V_{S}\right)$, to which all the results are referred to, is set to $1.0 \mathrm{I}$, while $0.7 \mathrm{I}$ and $1.3 \mathrm{I}$ represent conditions with reduced $\left(V_{r}\right)$ and increased $\left(V_{i}\right)$ total volume, respectively. Similarly, the standard solid fraction $\left(s_{S}\right)$ is considered at $15 \%$ of the employed total volume, while $5 \%$ and $25 \%$, represent the configurations of reduced $\left(s_{r}\right)$ and increased $\left(s_{j}\right)$ solid 
fraction, respectively. Each combination of $V$ and $s$ is repeated at two different stream power levels, labelled half stream power $\left(\Phi_{h}\right)$ and full stream power $\left(\Phi_{f}\right)$, respectively. These two stream power regimes are induced by changing the release time of the liquid water volume opening the water container tap at half $\left(45^{\circ}\right)$ and full $\left(90^{\circ}\right)$ rotation, respectively. The release time of the stored water volume approximately halves passing from a $45^{\circ}$ to a $90^{\circ}$ rotation of the tap opening. Following Santibañez et al. (2021) and Blasi et al. (under review), to assess the variability of the response variables, each experimental configuration is repeated 8 times, giving a total number of 144 experimental runs (Fig. 2).

\subsection{Exposure analysis and delineation of exposure probability maps}

The delineation of exposure on the alluvial fan surface required different steps: (i) orthogonal videorecording with a camera of the unfolding distributary dynamics associated with each experimental run; (ii) extraction of video-frames from the recorded videos by employing a Python script; (iii) geo-referencing of the extracted images in a precisely delimited alluvial fan area through the tools available in the QGIS software environment; (iv) overlay of a regular grid onto the geo-referenced images employing the Python Plugin TomBio tools (QGIS, 2018) for the subsequent counting of the exposed cells. A cell (size corresponding to $100 \mathrm{~mm}^{2}$ on the alluvial fan surface) was classified as exposed to the sediment-laden flow if more than half of its area was covered by the liquid or solid components of the sediment-laden flow; (v) specific exposure classification, thereby obtaining a polygon enclosing the exposed cells to the biphasic flow mixture. The exposed areas were quantified by direct measurement within QGIS and the obtained values were stored in an Excel spreadsheet. In parallel, a raster map corresponding to the determined exposure was derived. (vi) generation of total exposure probability maps, whereby the exposed areas on each raster map of each set of experiments with the same loading conditions were considered as equally probable outcomes.

Concerning this last step, we obtained an exposure probability map corresponding to each specific loading configuration. The total exposure (i.e. areas covered by water or sediment) is obtained by calculating the cell-based sum of the exposure probability contributions of each raster map. An example of a resulting exposure probability map is shown in Fig. 3.

Under the specified loading conditions, the areas with a zero-valued exposure probability (i.e. greycoloured) are safe, whereas the areas with a unitary exposure probability (i.e. red-coloured) are regarded as unconditionally exposed. The probability values of the remaining areas reflect their likelihood of being exposed under specific loading conditions. Additionally, the magnitude and variability of the response (i.e. exposure) associated with all experimentally imposed loading conditions are visualized through boxplots and bar charts.

\subsection{Statistical Analysis: Multiway ANOVA and interactions between factors}


In this subsection, we describe how we statistically analysed our experimental results. For an extended presentation of the employed procedures, we refer to Dean et al. (2017). We investigated the contribution that each of the considered factors (i.e. total released volume, solid fraction and stream power) individually make to the response (i.e. exposed area due to sediment deposition and water flow) considering also the interaction of each pair of factors. The analyses (i.e. ANOVA) have been performed in the software STATGRAPHICS centurion ${ }^{\circledR}$. Specifically, the Multifactor ANOVA procedure is designed to construct a statistical model describing the impact of two or more categorical factors $X j$ on a dependent variable $Y$ (Statgraphics 2009).

Of particular importance are F-ratios and their associated P-Values. P-Values less than 0.01 (i.e. operating at the $1 \%$ significance level) correspond to a highly significant effect, whereas P-Values comprised between 0.01 and 0.05 (i.e. operating at a $5 \%$ significance level) are associated with a significant effect.

The results are conveniently displayed in form of an ANOVA table. The table divides the overall variability of the response variable among the accomplished set of measurements into several components: (i) a component attributable to the main effect of each factor, which measures the variability amongst the mean responses at each level of the factor; (ii) a component attributable to the interaction between different factors (i.e. an interaction occurs if the effect of one factor depends on the level of another factor); (iii) if covariates are present, a component attributable to each covariate; (iv) a residual component, which measures the variability amongst subjects at identical levels of the factors.

The data are displayed graphically as interaction plots with Tukey-intervals that visually reveal how the different factor combinations affect the average response (i.e. the exposed area in \%).

\section{Results}

\subsection{Exposure probability and variability}

According to the stated objectives of the accomplished research, we first show the obtained total exposure probability maps as a suitable form to visualize the spatial variability and uncertainty of the alluvial fan areas affected by the sediment-laden flow. Figure 4 shows the total exposure probability maps associated with the experiments conducted with reduced total volume $\left(V_{r}\right)$ in the first and second column, with standard total volume $\left(V_{s}\right)$ in the third and fourth column, and with increased total volume ( $V_{i}$ ) in the fifth and sixth columns. In the first, third and fifth columns the total exposure probability maps resulting from the full stream power experiments, $\left(\Phi_{f}\right)$, are arranged, whereas in the second, fourth and sixth column the probability maps generated by imposing half stream power $\left(\Phi_{h}\right)$ are displayed.

As highlighted by Fig. 4 the spatial variability of the total exposure probability associated with half stream power conditions and to the release of the standard total volume is remarkable when compared to the total exposure probability maps generated by the corresponding full stream power experiments. The certainly exposed areas concentrate as expected in the channel areas and the distal part of the alluvial 
fan surface. Increasing the solid fraction concerning standard conditions no noticeable increase of the exposed areas can be detected although a right-hand channel outburst can expose an additional small portion with low exposure probability.

When reducing the solid fraction concerning the standard condition the certainly exposed areas, counterintuitively, increase slightly.

Instead in the latter case (i.e. half stream power conditions), the patterns of total exposure probability change significantly when reducing or increasing the solid fraction concerning the standard conditions. In both cases, a noticeable change of the certainly exposed areas can be observed, but in the first case, the areas with non-zero exposure probability are restricted to the channel and the most peripheral sectors of the alluvial fan. On the contrary, in the second case, due to multiple channel outbursts in the proximal alluvial fan sector and subsequent radiating propagation, areas with non-zero exposure probability tend to correspond, except in the most peripheral sector, to those areas which remained unaffected with full stream power conditions and, overall, the areas with a zero-valued exposure probability are much more restricted.

As depicted in Fig. 4 an increase of the released total volume concerning standard conditions generates a slight increase of the certainly exposed areas in the full stream power case, whereas a decrease of the released total volume does not lead to a noticeable decrease of the exposed areas with probability equal to one. Under this stream power regime, the non-exposed areas (i.e. probability of exposure equal to zero) are very similar both in position and extent which indicates that the uncertainty of the propagation patterns is comparably low. When imposing the half stream power regime, areas with a non-zero probability of exposure increase (decrease) when passing from standard to increased (reduced) released volumes. Also, the spatial uncertainty associated with the exposed areas augments (diminishes) when changing the released volume from standard to increased (reduced) conditions. With half stream power conditions, one can appreciate that the change in the patterns of exposure probability generated by a change in the released volume is more homogeneous concerning a change in the solid fraction.

In Fig. 4 the exposure probability maps associated with an augmented (diminished) released volume and an increased (decreased) solid fraction are compared to the exposure probability maps generated by standard conditions and by imposing full and half stream power, respectively. Again, the spatial patterns of exposure probability that emerge from full stream power experiments are more homogenous than the counterparts obtained by applying half stream power. In the full stream power case, no significantly different patterns can be detected when passing from standard conditions to a reduced released volume and solid fractions. On the contrary, when increasing both the released volume and the sediment fraction concerning standard conditions, the exposed areas with non-zero probability increase and occupy also slightly more proximal alluvial fan areas due to more frequent channel outbursts. Again, half stream power conditions generate a remarkable variability of the exposed areas with non-zero probability. These areas consistently increase (decrease) when passing from standard experimental conditions to both and 
increased (decreased) released volume and sediment fraction. The patchiness of the non-exposed areas is remarkable with more severe experimental loading conditions.

In Fig. 4 the comparison of the total exposure probability maps associated to standard conditions for both full and half stream power regimes (i.e. two central panels) in comparison the exposure probability patterns generated by a combination of reduced released volume, increased sediment fraction (i.e. two lowest maps in the first and second column) and by a combination of an increased released volume but a reduced sediment fraction (i.e. two uppermost maps in the fifth and sixth column) is depicted. Concerning this comparison, the total exposure probability maps associated with full stream power exhibit a remarkable similarity. The exposed and non-exposed areas are almost identical. Instead, when the half stream power regime is imposed, the three situations are very peculiar. Concerning standard conditions, an increase of the released volume combined with a diminished solid fraction leads to a far less severe exposure on the alluvial fan surface with much more extended safe areas (i.e. areas with zerovalued total exposure probability). This result underlines that the event magnitude in terms of the released total volume alone is a rather unreliable predictor of the overall exposure of considered alluvial fan layout. Decreasing the released total volume and augmenting the sediment fraction concerning standard conditions leads to a less exposed alluvial fan surface but the spatial patterns of exposure exhibit a remarkable variability. It is also noticeable that this experimental configuration gives rise to a more severely exposed alluvial fan surface concerning the release of an increased event volume but a diminished solid fraction. Herein, the capability of the guiding channel to export the entrained sediment volumes plays a crucial role.

Probability maps allow for an insightful visual interpretation of the variability of exposure on the alluvial fan surface but do not permit rigorous quantitative comparisons. For this reason, in Fig. 5 we show an arrangement of three boxplots where the variability (i.e. quantiles) and the median of the total exposure (i.e. due to both sediment deposition and water flow areas) are associated with the reduced released volume (upper boxplot), the standard released volume (central boxplot) and the increased released volume (lower boxplot) considering all solid material fractions (i.e. from left to right the reduced, standard and increased, respectively) and the imposed stream power regime (i.e. half versus full stream power). Overall the three boxplots highlight that the interquartile ranges of the total exposure are larger when half stream power conditions are imposed. Moreover, it can be observed that irrespectively of the released total volume the median of the total exposure associated to experiments with a reduced solid fraction conducted with half stream power is consistently lower than the total exposure generated by the full stream power counterpart experiments. When a standard solid fraction is predisposed instead, the median of the mean exposure associated to half stream power experiments is, independently of the released total volume, higher than the mean exposure observed in the corresponding full stream power experiments. The differences, however, are small when a reduced total volume is released, whereas they are much more pronounced when a standard or increased total volume is discharged.

A mixed situation can be observed when an increased solid fraction is predisposed. In fact, in this case, half stream power experiments lead to a higher median of the total exposure values when a standard or 
an increased total volume is released. Whereas, when a reduced total volume is discharged, the opposite is the case.

With both stream power regimes, the expected trend of an increase of the median of the total exposure as a function of the employed solid fraction can be retraced only when an increased total volume is released. Even more unexpectedly, when predisposing a reduced solid fraction and imposing a half stream power regime and augmenting the released volume from reduced to standard conditions and also from standard to increased conditions, the interquartile range of total exposure shrinks and the median of the total exposure value decreases and then increases slightly.

Another way to describe both magnitude and variability of the total exposure is through bar charts visualizing the mean value and thereby displaying the standard deviations of the measured exposed areas on the alluvial fan surface (compare Fig. 6).

Regarding Fig. 6 one can observe that the mean total exposure obtained from the experiments conducted with a reduced solid fraction and full stream power is higher than the mean total exposure generated by the corresponding half stream power experiments. Also, with a reduced solid fraction and full stream power, the mean total exposure counterintuitively decreases slightly augmenting the released total volume. With the same solid fraction and when half stream power is imposed, we observe a slight decrease of the mean total exposure when passing from $V_{r}$ to $V_{S^{\prime}}$ followed by a slight increase when the released total volume is changed from $V_{s}$ to $V_{i}$.

A different situation is noticed when describing the results of the experiments conducted with a standard solid fraction $\left(s_{S}\right)$. Expectedly, the mean total exposure increases augmenting the released total volume irrespectively of the applied stream power regime. In this case, however, the increasing trend is much more pronounced for the experiments conducted with half stream power. When releasing a reduced total volume, the mean total exposures obtained from full and half stream power experiments are almost equal.

The same increasing trend of the experimental response associated with an augmented total volume release is confirmed for both stream power regimes when the increased solid fraction is predisposed. In this case, the bar chart shows that with the release of a reduced total volume the mean total exposure associated with full stream power experiments is higher than the corresponding values of this response variable generated by half stream power experiments. For the solid fractions $s_{S}$ and $s_{i}$ the experimental results are reverted.

The standard deviation of the mean total exposure (i.e. the extent of the whiskers) associated with experiments conducted with half stream power is generally larger than the standard deviation of the counterpart experiments conducted with full stream power.

\subsection{Multiway ANOVA statistics and interactions between factors}


To determine whether or not the factors have a significant effect on the dependent variable, an analysis of variance is performed. The results are displayed in the following ANOVA table (see Table 1).

Table 1

Results of the performed ANOVA analysis: Factors, F-ratios and their associated P-Values (**: highly significant differences associated to

P-Values $\leq 0.01$ by operating at a confidence level of $1 \%$; *: significant differences associated to the range $0,01<$ P-Values $\leq 0,05$

by operating at a confidence level $5 \%$; NS: absence of significant differences associated to P-Values $>0.05$.

\begin{tabular}{|llll|}
\hline Factors & F-Ratio & P-Value & Significance \\
\hline A: Stream power $-\Phi$ & 1,29 & 0,257 & NS \\
\hline B: Total released volume $-V$ & 109,23 & $\mathrm{P}<0,000$ & $* *$ \\
\hline C: Solid fraction $-S$ & 207,64 & $\mathrm{P}<0,000$ & $* *$ \\
\hline Interactions & & & \\
AB & 20,20 & $\mathrm{P}<0,000$ & $* *$ \\
\hline AC & 102,45 & $\mathrm{P}<0,000$ & $* *$ \\
\hline BC & 41,67 & $\mathrm{P}<0,000$ & $* *$ \\
\hline
\end{tabular}

The results of the performed ANOVA analysis (see Table 1 and Fig. 7) reveal that the released total volume and the predisposed solid fraction exert a significant main effect on exposure whereas stream power does not. Confidently we can also retrace components of the overall variability of the response to the interaction between the considered factors (i.e. $(\Phi, V),(\Phi, s),(V, s))$. To reiterate, an interaction occurs if the effect of one factor depends on the level of another factor.

When analysing the effect on the mean total exposure due to the interaction between the released total volume and the applied stream power (see Fig. 7, Panel A) one can notice that, without further discernment, different effects can be expected on average by the following three groups of experimental conditions: i) $\Phi_{h}, V_{r}$; ii) $\Phi_{h}, V_{i}$; (iii) the group of the remaining pairs of levels of the two considered factors.

Considering the full stream power experiments $\Phi_{f}$ with the different levels of the factor released total volume, one can appreciate that a significantly different effect can be achieved only between $V_{r}$ and $V_{i}$ (i.e. the respective Tuckey intervals do not overlap), whereas with the half stream power regime $\Phi_{h}$ the response is significantly different, on average, among the different levels of released total volume (i.e. the Tuckey-intervals do not overlap for all level comparisons). When fixing the level of released total volume, we can appreciate that with $V_{r}$ and $V_{i}$ significantly different responses can be achieved on average between experiments conducted with half and full stream power, respectively. On the contrary, releasing $V_{r}$ does not permit discerning, on average, different responses. 
When analysing the effect on the mean total exposure due to the interaction between the predisposed solid fraction and the applied stream power (see Fig. 7, Panel B), the interaction plot displays, without further discernment, that the following experimental configurations can be grouped, since, on average, different experimental responses (i.e. mean total exposure) can be expected: i) $\Phi_{h}, S_{r}$ ii) $\Phi_{f} S_{r}$ and $\Phi_{f}$ $s_{S} ;$ iii) the group of the remaining pairs of levels of the two considered factors.

Considering only the full stream power experiments $\Phi_{f}$ a highly significant difference in the response can be observed if an increased sediment fraction is predisposed in comparison to the effects achieved with a standard and reduced solid fraction, whereas a different response cannot be discerned between $s_{r}$ and $s_{S}$. When focusing specifically on the experiments conducted with half stream power a different response (i.e. highly significant) is yielded instead when a reduced solid fraction is predisposed (i.e. $s_{r}$ ) compared to both the experiments conducted with $s_{S}$ and $s_{i}$, whereas the response between experiments conducted predisposing $s_{S}$ or $s_{i}$ is not statistically different. Fixing the released total volume level, we observe significant effects on total exposure associated with full and half stream power experiments, respectively, only if $s_{r}$ and $s_{S}$ is predisposed.

The last studied interaction refers to the conjoint effect on the response of solid fraction and released total volume. Without explicitly fixing one of the levels of the considered factors, different effects can be expected on average by the following two groups of experimental conditions only: i) $s_{i}, V_{\dot{i}}$ ii) all the remaining factor level combinations grouped. Fixing the levels of the released total volume allows for a greater degree of discernment. If $V_{i}$ is released the response (i.e. mean total exposure) associated to $s_{r} s_{S}$ , and $s_{i}$, respectively, is, on average different and increasing. If a standard total volume is released the response associated to $s_{r}$ differs on average, from the response generated by experiments with a standard or increased solid fraction. No further distinction is possible between the configurations $s_{S^{\prime}}$ and $s_{i}$ : If a reduced total volume is released, experiments conducted with different solid fractions do not lead, on average, to different responses.

Fixing the predisposed sediment fraction to $s_{S^{\prime}}$ and $s_{i}$, respectively, allows for a full distinction of the effects imputable to the different levels of the other factor (i.e. released total volume). Instead, with $s_{r}$ fixed, the effects due to different levels of the released total volume are not statistically distinguishable.

\section{Discussion And Conclusions}

In this study, we provided compelling evidence that the flow propagation generated by indiscernible experimental conditions indeed exhibits a substantial variability. First, we visualized this variability in form of total exposure probability maps, boxplots and bar charts with whiskers representing the total exposure's standard deviation. Thereupon we analysed through a suitable statistical method (i.e. ANOVA) if and to what extent the considered experimental factors exerted a significant effect on the response in terms of the mean total exposure of the alluvial fan surface. Whereas we could corroborate the main effects due to both the solid fraction and the released total volume, no main effect due to stream power 
could be retracted. We could also statistically underpin that all interactions among the aforementioned factors explain a component of the overall variability of the response and we visualized them in detail through interaction plots.

These results have far-reaching implications for hazard and risk assessment on alluvial fans where sediment-laden flows may constitute the main formative processes:

First and foremost, the inherent variability of the flow propagation on the alluvial fan surface strongly suggests that components of randomness do play a relevant role in the distributary dynamics of extreme events on real-world alluvial fans as well (Fuchs et al. 2013). Sources of randomness can for instance reside in the effects of autogenic processes, in the inhomogeneity of grain size distributions and marginal changes during the hazard event as a suddenly mobilized boulder or disrupted log jam, minor fluctuations of model boundary conditions (i.e. unaccounted sediment-laden flow pulses), or any unexpected clogging of a flow section, which could induce singular behaviours so that patterns of deposition and exposure could change unpredictably. Although we concede that it was not possible to establish the causalities between the aforementioned sources of uncertainty and the variability of the observed patterns of exposure, we could experimentally prove the existence of this variability and quantify it accordingly for the considered alluvial fan layout.

Although the experimentally observed magnitude of variability is not representative of other experimental settings (i.e. different geometry and dimensions of the alluvial fan models, different types of flow, the scaling issue), recent experimental findings indicate that this randomness generally exists:

Santibañez et al. (2021), for example, conducted experiments on an analogous small-scale alluvial fan model (i.e. without the presence of the curved guiding channel) varying systematically the total discharge volume, the sediment fraction of the biphasic mixture and the applied stream power. In their experiments, a fixed proportion of the solid fraction was constituted by large wood. Their results confirm that the patterns of exposure associated with specific loading conditions exhibit remarkable randomness and that the fixed portion of large wood strongly also interfere with the distributary dynamics on the alluvial fan surface.

Blasi et al. (under review) accomplished experiments on two small scale alluvial fan layouts, one with a guiding channel equipped with a crossing bridge and one featuring the guiding channel without crossing structures. This study also confirmed that the patterns of exposure associated with specific loading conditions exhibit a remarkable variability.

Moser (2018) studied fluviatile hazard processes on a torrential fan (i.e. Schnannerbach alluvial fan, Tyrol, Austria), executing many complex experiments on a large Froude-scaled (1:30) model. The model accurately reproduced the natural conditions and covered a set of buildings on the torrential fan (for more details on the experimental set-up see Sturm et al. 2018a, b). The sediment deposition patterns of five experiments, each accomplished identically and with experimentally indiscernible boundary conditions, were analysed. By referring to one experiment as a reference case, the obtained spatial patterns of 
differences were remarkable. This highlights that the geomorphic work accomplished throughout the unfolding of each experimental run is essentially unique.

Based on this premise we contend that hazard assessment on alluvial fans based on a single deterministic flow simulation for specified initial and boundary conditions (i.e. inflow fluxes for a given return period) might be insufficient for reliably detecting the intervening autogenic processes and the abovementioned tipping process patterns that may change the exposed areas to a significant extent. In the authors view this problem might be serious on unconfined landforms, such as alluvial fans and fandeltas, in particular if hazard mapping decisions are based on one single simulation with a given setup, without any sensitivity analysis and additional expert judgement.

Hazard maps elaborated according to the existing standards may be based on the aforementioned drawbacks, fail to adequately mirror hazard-prone areas or overemphasize the exposure of certain indicated sectors (i.e. by definition the probability of exposure is equal to one). This may contribute to jeopardize the effectiveness of public and private investments into supposedly hazard proof buildings and settlements.

In the introduction, we mentioned the Rio Blanco case in Chaitén (Lake district, Chile) as a paradigmatic example. Basso-Báez et al. (2019), for example, analysed the tipping point behaviour of the flow obstruction and diversion effects of different bridge clogging scenarios. Through tailored simulations of considered hydrologic scenarios, they could demonstrate that the cross-sectional blockage at the "Austral Road" bridge represents a pivotal factor in determining the extent of the inundated areas and associated impacts in the urban area of Chaitén which is partly located on a fan-delta.

In light of the experimentally detected process variability, a word of caution must be mentioned here also concerning the calibration of numerical models based on documented events. Forcing the simulation model to reproduce an observed event by calibrating the model parameters could be misleading, since different initial and boundary conditions contrived to identity in the simplified modelling environment could exhibit, upon occurrence, fundamentally different process patterns. A sensitivity analysis concerning the overlooked differences in both initial and boundary conditions would be precluded and hazard and risk assessments would potentially be inaccurate.

Again, concerning the Rio Blanco case in Chaitén, Basso-Báez et al. (2019) point out that complete disclosure of the different sources of uncertainty that may affect the predictability of hazardous phenomena (e.g. Pate-Cornell 1996; Merz et al. 2008) is essential for an informed decision-making process. As outlined by Fuchs et al. (2008) and Mazzorana and Fuchs (2010b), several sources of uncertainties should be considered concerning hydrological hazards and torrent processes including (i) uncertainties about the possible range of rheological behaviour and about the liquid-solid mixture concentration of the analysed flow phenomenon, (ii) uncertainties in system loading assumptions (e.g. duration-intensity related uncertainties, uncertainties related to sediment transport rates, uncertainties emerging from LW transport), (iii) uncertainties in system response mechanisms (e.g. localised obstructions that divert the flow patterns, influence of small-scale topological features), and (iv) 
uncertainties related to morphological changes in the response system. In this study, we specifically addressed the last source reported on this list and explored the effects on the generated exposure on the experimental alluvial fan surface.

To limit this source of uncertainty, we propose that the development of numerical models capable of mirroring more reliably the stochastic sediment-laden flow behaviour on alluvial fans should be conducted considering the ongoing experimental research on alluvial fans. Large-scale experimental alluvial fan models could be regarded as a valuable touchstone for model development. Specifically, we suggest, that the quality of a numerical model setup should be judged concerning its capability to reproduce not a single hazard event but sets of experimental responses associated with the same, experimentally indiscernible, initial and boundary conditions. So rather than minimizing the discrepancies with respect to one, deterministically obtained, model output, it should be attempted to minimize the probability of a mismatch between a set of simulations outputs and the associated probabilistic experimental results.

Adopting this probabilistic calibration concept, particular attention should be devoted also to enhancing the model-based detection of the autogenic phenomena occurring on the alluvial fan surface during process propagation. Again, regarding the flood hazard analysis in Chaitén (see Basso-Baez et al. 2019), such an enhanced modelling concept, integrating both experimental and numerical results, would have helped to better detect potential autogenic processes such as channel-backfilling and avulsions with profound repercussions on the resulting hazard propagation patterns. Of course, our "similitude by process" based experiments serve only as a gross analogy of the suite of processes that intervened during the unfolding of the inundation of Chaitén and extended benchmark research, with different model developers testing their products against large sets of experimental data obtained from a Froude-scaled experimental model would be warmly welcomed.

Our results suggest at least as a promising starting point, that allogenic factors such as stream power or discharge in the feeding channel may be rather ambiguous control factors. On our experimental alluvial fan, no main effect on the mean total exposure imputable to this factor could be retracted.

The elaborated exposure probability maps show that experiments conducted imposing half stream power generate extended areas with a non-zero probability of exposure. Moreover, the associated spatial patterns indicate a remarkable uncertainty and the areas assumed as safe (i.e. with a zero-valued probability of exposure) are patchier and, in several cases, less extended.

The performed statistical analysis (ANOVA) further indicated that the different interactions between the considered factors exert a significant effect on the mean total exposure. Overlooking the role of these interactions and basing investment decisions aiming at effective risk mitigation on a "design discharge" alone, as it is common practice in many mountain regions of the world, is a risky endeavour (Mazzorana et al. 2013). 
Due to the profound implications for our ability as a society to proactively adapt and enhance our resilience to the impacts of flood hazards in mountainous and alpine environments, fostering tailored research aiming at experimentally and numerically unravelling the complexity and hidden variability of sediment-laden flows on unconfined landforms (i.e. alluvial fans) becomes essential.

The first fundamental research challenge consists in making this process complexity and hidden variability experimentally observable, since the available historical record, no matter how extended, remains largely incomplete (De Haas et al. 2018). Once dealt with this first challenge, a detailed detection of the underlying spatial and temporal variabilities is important for the generation of datasets with minimized imprecision and maximized accuracy. In a subsequent research step, these data sets should be analysed with suitable analytical and statistical methods. Thereupon, endowed with reliable quantifications of the emerged variability of the observed process propagations and the identification of all relevant sources of uncertainty, the attempt has to be made to devise computational modelling strategies capable of adequately mirroring process stochastics by nudging or coaxing the deterministic simulation models or by introducing elements of randomness. The gained insights and the generated knowledge would be essential requisites for further developing the societies' ability of proactive adaptation.

\section{Declarations}

Funding: ANID - FONDECYT PROGRAM: Grant Nr. 1200091

Conflicts of Interest: The Authors have no conflict of interest to declare

Availability of data and material: Data from experimentation with the alluvial fan model can be made available on request.

Code availability: Python code scripts used for analysis can be made available on request.

Acknowledgements: The research was funded by the FONDECYT Project Nr. 1200091 "Unravelling the dynamics and impacts of sediment-laden flows in urban areas in southern Chile as a basis for innovative adaptation (SEDIMPACT)", led by Bruno Mazzorana.

Authors contributions: Conceptualization: Bruno Mazzorana, Hector Diaz; Methodology: Hector Diaz, Bruno Mazzorana; Formal analysis and investigation: Hector Diaz, Ivan Rojas, Nicole Santibañez, Bruno Mazzorana; Writing - review and editing: Bruno Mazzorana, Bernhard Gems, Ivan Rojas, Pablo Iribarren, Mario Pino, Andrés Iroumé.

\section{References}

1. Alexander D (2000) Confronting Catastrophe. Oxford University Press, Oxford 
2. Antronico L, Greco R, Robustelli G et al (2015) Short-term evolution of an active basin-fan system, Aspromonte, south Italy. Geomorphology 228:536-551. 10.1016/j.geomorph.2014.10.013 536-551.

3. Basso-Báez S, Mazzorana B, Ulloa H, Bahamondes D, Ruiz-Villanueva V, Sanhueza D, Iroumé A, Picco $L$ (2020) Unravelling the impacts to the built environment caused by floods in a river heavily perturbed by volcanic eruptions. J S Am Earth Sci 102:102655. https://doi.org/10.1016/j.jsames.2020.102655

4. Blair TC, McPherson JG (1994) Alluvial Fans and their Natural Distinction from Rivers Based on Morphology, Hydraulic Processes, Sedimentary Processes, and Assemblages F. J Sediment Res 64A(3a):450-489. https://doi.org/10.1306/D4267DDE-2B26-11D7-8648000102C1865D

5. Blair TC, McPherson JG (2009) Processes and Forms of Alluvial Fans. In Geomorphology of Desert Environments. (pp 413-467). Springer Netherlands. https://doi.org/10.1007/978-1-4020-5719-9_1

6. Bowman D (2019) Aggradation. In Principles of Alluvial Fan Morphology (pp. 57-60). Springer Netherlands. https://doi.org/10.1007/978-94-024-1558-2_7

7. Bryant M, Falk P, Paola C (1995) Experimental study of avulsion frequency and rate of deposition. Geology 23(4):365-368. https://doi.org/10.1130/00917613(1995)023<0365:ESOAFA>2.3.C0;2

8. Bubeck P, Aerts JCJH, De Moel H, Kreibich H (2016) Preface: Flood-risk analysis and integrated management. Nat Hazard Earth Sys 16(4):1005-1010. https://doi.org/10.5194/nhess-16-1005-2016

9. Bull WB (1977) The alluvial-fan environment. Progr Phys Geog 1(2):222-270. https://doi.org/10.1177/030913337700100202

10. Clarke L, Quine TA, Nicholas A (2010) An experimental investigation of autogenic behaviour during alluvial fan evolution. Geomorphology 115(3-4):278-285.

https://doi.org/10.1016/j.geomorph.2009.06.033

11. Clarke $L$ (2015) Experimental alluvial fans: Advances in understanding of fan dynamics and processes. Geomorphology 244:135-145. https://doi.org/10.1016/j.geomorph.2015.04.013

12. Clevis $Q$, de Boer P, Wachter $M$ (2003) Numerical modelling of drainage basin evolution and threedimensional alluvial fan stratigraphy. Sediment Geol 163(1-2):85-110. https://doi.org/10.1016/S0037-0738(03)00174-X

13. D’Agostino V, Cesca M, Marchi L (2010) Field and laboratory investigations of runout distances of debris flows in the Dolomites (Eastern Italian Alps). Geomorphology 115(3-4):294-304. https://doi.org/10.1016/j.geomorph.2009.06.032

14. Davies TRH, McSaveney MJ, Clarkson PJ (2003) Anthropic aggradation of the Waiho River, Westland, New Zealand: microscale modelling. Earth Surf Proc Land 28(2):209-218. https://doi.org/10.1002/esp.449

15. Dean A, Voss D, Draguljić D (2017) Design and Analysis of Experiments. Springer International Publishing AG, New York

16. De Haas T, Densmore AL, Stoffel M, Suwa H, Imaizumi F, Ballesteros-Cánovas JA, Wasklewicz T (2018) Avulsions and the spatio-temporal evolution of debris-flow fans. Earth-Sci Rev 177:53-75. https://doi.org/10.1016/j.earscirev.2017.11.007 
17. Drew $F$ (1873) Alluvial and lacustrine deposits and glacial records of the Upper-Indus Basin. Q j Geol Soc Lond 29(1-2):441-471. https://doi.org/10.1144/GSL.JGS.1873.029.01-02.39

18. Feng W, Wu S, Liu J et al (2019) The depositional evolution and internal sedimentary architecture of a flood event-dominated experimental alluvial fan. Arab J Geosci 12:284. https://doi.org/10.1007/s12517-019-4468-z

19. Fuchs S, Kaitna R, Scheidl C, Hübl J (2008) The application of the risk concept to debris flow hazards. Geomechanics Tunnelling 1(2):120-129. https://doi.org/10.1002/geot.200800013

20. Fuchs S (2009) Susceptibility versus resilience to mountain hazards in Austria - Paradigms of vulnerability revisited. Nat Hazard Earth Sys 9(2):337-352. https://doi.org/10.5194/nhess-9-3372009

21. Fuchs S, Keiler M, Sokratov S et al (2013) Spatiotemporal dynamics: the need for an innovative approach in mountain hazard risk management. Nat Hazards 68:1217-1241. https://doi.org/10.1007/s11069-012-0508-7

22. Galloway WE, Hobday DK (1996) Alluvial Fans. In Terrigenous Clastic Depositional Systems (pp. 2959). Springer Berlin Heidelberg. https://doi.org/10.1007/978-3-642-61018-9_3

23. Guerit L, Métivier F, Devauchelle O, Lajeunesse E, Barrier L (2014) Laboratory alluvial fans in one dimension. Phys Rev E 90(2):022203. https://doi.org/10.1103/PhysRevE.90.022203

24. Harvey A (2012) Introducing Geomorphology: A Guide to Landforms and Processes. (Introducing Earth and Environmental Sciences). Dunedin Academic Pr Ltd

25. Hooke RL (1968) Model Geology: Prototype and Laboratory Streams: Discussion. Geo Soc Am Bull 79(3):391-394. https://doi.org/10.1130/0016-7606(1968)79[391:MGPALS]2.0.C0;2

26. Kienholz H, Krummenacher B, Kipfer A, Perret S (2004) Aspects of integral risk management in practice: Considerations with respect to mountain hazards in Switzerland. Österreichische WasserAbfallwirtschaft 56(3):43-50

27. MacDonald D, Crabtree JR, Wiesinger G, Dax T, Stamou N, Fleury P, Gutierrez Lazpita J, Gibon A (2000) Agricultural abandonment in mountain areas of Europe: Environmental consequences and policy response. J Environ Manage 59(1):47-69. https://doi.org/10.1006/jema.1999.0335

28. Mazzorana B, Fuchs S (2010a) A conceptual planning tool for hazard and risk management. Chen SC (ed.), Internationales Symposion Interpraevent in the Pacific Rim, Klagenfurt: Internationale Forschungsgesellschaft Interpraevent: 828-837

29. Mazzorana B, Fuchs S (2010b) Fuzzy Formative Scenario Analysis for woody material transport related risks in mountain torrents. Environ Model Softw 25(10):1208-1224. https://doi.org/10.1016/j.envsoft.2010.03.030

30. Mazzorana B, Comiti F, Fuchs S (2013) A structured approach to enhance flood hazard assessment in mountain streams. Nat Hazards 67:991-1009. https://doi.org/10.1007/s11069-011-9811-y

31. Mazzorana B, Simoni S, Scherer C, Gems B, Fuchs S, Keiler M (2014) A physical approach on flood risk vulnerability of buildings. Hydrol Earth Syst Sci 18(9):3817-3836. https://doi.org/10.5194/hess18-3817-2014 
32. Mazzorana B, Iribarren P, Oyarzun C, Ulloa H, Batalla R, Gems B, Sturm M, Iroumé A (2017a) Determining patterns of flood hazard exposure on experimental alluvial fan. XX Congreso Geologico Argentino - Geologia, Presente y Futuro, pp 24-28

33. Mazzorana B, Ruiz-Villanueva V, Marchi L, Cavalli M, Gems B, Gschnitzer T, Mao L, Iroumé A, Valdebenito G (2018) Assessing and mitigating large wood-related hazards in mountain streams: recent approaches. J Flood Risk Manag 11(2):207-222. https://doi.org/10.1111/jfr3.12316

34. Mazzorana B, Ghiandoni E, Picco L (2020) How do stream processes affect hazard exposure on alluvial fans? Insights from an experimental study. J Mt Sci 17(4):753-772. https://doi.org/10.1007/s11629-019-5788-x

35. Merz B, Kreibich H, Apel H (2008) Flood risk analysis: Uncertainties and validation. Österreichische Wasser- Abfallwirtschaft 60(5-6):89-94. https://doi.org/10.1007/s00506-008-0001-4

36. Mokarram M, Pourghasemi HR, Tiefenbacher JP (2021) Morphometry of AFs in upstream and downstream of floods in Gribayegan, Iran. Nat Hazards 108:425-450. https://doi.org/10.1007/s11069-021-04690-0

37. Moser M (2018) (unpublished) Untersuchung der Reproduzierbarkeit von fluviatilen Ablagerungsprozessen im Labor unter Verwendung photogrammetrischer und mechanischer Analysemethodik. Master Thesis, Unit of Hydraulic Engineering, University of Innsbruck

38. Muto T, Steel RJ, Swenson JB (2007) Autostratigraphy: A framework norm for genetic stratigraphy. J Sediment Res 77(1-2):2-12. https://doi.org/10.2110/jsr.2007.005

39. National Research Council (1996) Alluvial Fan Flooding. In Alluvial Fan Flooding. National Academies Press. https://doi.org/10.17226/5364

40. Okunishi K, Suwa H (2001) Assessment of Debris-Flow Hazards of Alluvial Fans. Nat Hazards 23:259-269. https://doi.org/10.1023/A:1011162516211

41. Paola C, Straub K, Mohrig D, Reinhardt L (2009) The "unreasonable effectiveness" of stratigraphic and geomorphic experiments. Earth-Sci Rev 97:1-43. 10.1016/j.earscirev.2009.05.003

42. Pate-Cornell E (1996) Uncertainty in risk analysis: Six levels of treatment. Reliab Eng Syst Safe 54(23):95-111. https://doi.org/10.1016/S0951-8320(96)00067-1

43. QGIS (2018) QGIS Python Plugins Repository. Accessed online at: https://plugins.qgis.org/plugins/TomBio/

44. Reitz MD, Jerolmack DJ (2012) Experimental alluvial fan evolution: Channel dynamics, slope controls, and shoreline growth. J Geophysi Res - Earth 117:F02021.

https://doi:10.1029/2011JF002261

45. Ruiz-Villanueva V, Mazzorana B, Bladé E, Bürkli L, Iribarren-Anacona P, Mao L, Nakamura F, Ravazzolo D, Rickenmann D, Sanz-Ramos M, Stoffel M, Wohl E (2019) Characterization of wood-laden flows in rivers. Earth Surf Proc Land 44(9):1694-1709. https://doi.org/10.1002/esp.4603

46. Santibañez N, Mazzorana B, Iribarren P, Rojas I, Mao L (2021) Dinámica distributiva de flujos bifásicos con carga de madera en un abanico aluvial experimental. Ingenieria del Agua 25(2):145168. https://doi.org/10.4995/la.2021.14703

Page 21/28 
47. Santo A, Santangelo N, Di Crescenzo G et al (2015) Flash flood occurrence and magnitude assessment in an alluvial fan context: the October 2011 event in the Southern Apennines. Nat Hazards 78:417-442. https://doi.org/10.1007/s11069-015-1728-4

48. Statgraphics (2009) Multifactor ANOVA.

https://cdn2.hubspot.net/hubfs/402067/PDFs/Multifactor_ANOVA.pdf. Accessed 25 February 2021

49. Sturm M, Gems B, Keller F, Mazzorana B, Fuchs S, Papathoma-Köhle M, Aufleger M (2018a)

Experimental analyses of impact forces on buildings exposed to fluvial hazards. J Hydrol 565:1-13. https://doi.org/10.1016/j.jhydrol.2018.07.070

50. Sturm M, Gems B, Keller F, Mazzorana B, Fuchs S, Papathoma-Köhle M, Aufleger M (2018b) Understanding impact dynamics on buildings caused by fluviatile sediment transport. Geomorphology 321:45-59. https://doi.org/10.1016/j.geomorph.2018.08.016

51. Van Dijk M, Postma G, Kleinhans MG, Kraal E (2012) Contrasting morphodynamics in alluvial fans and fan deltas: effect of the downstream boundary. Sedimentology 59(7):2125-2145. https://doi.org/10.1111/j.1365-3091.2012.01337.x

\section{Figures}

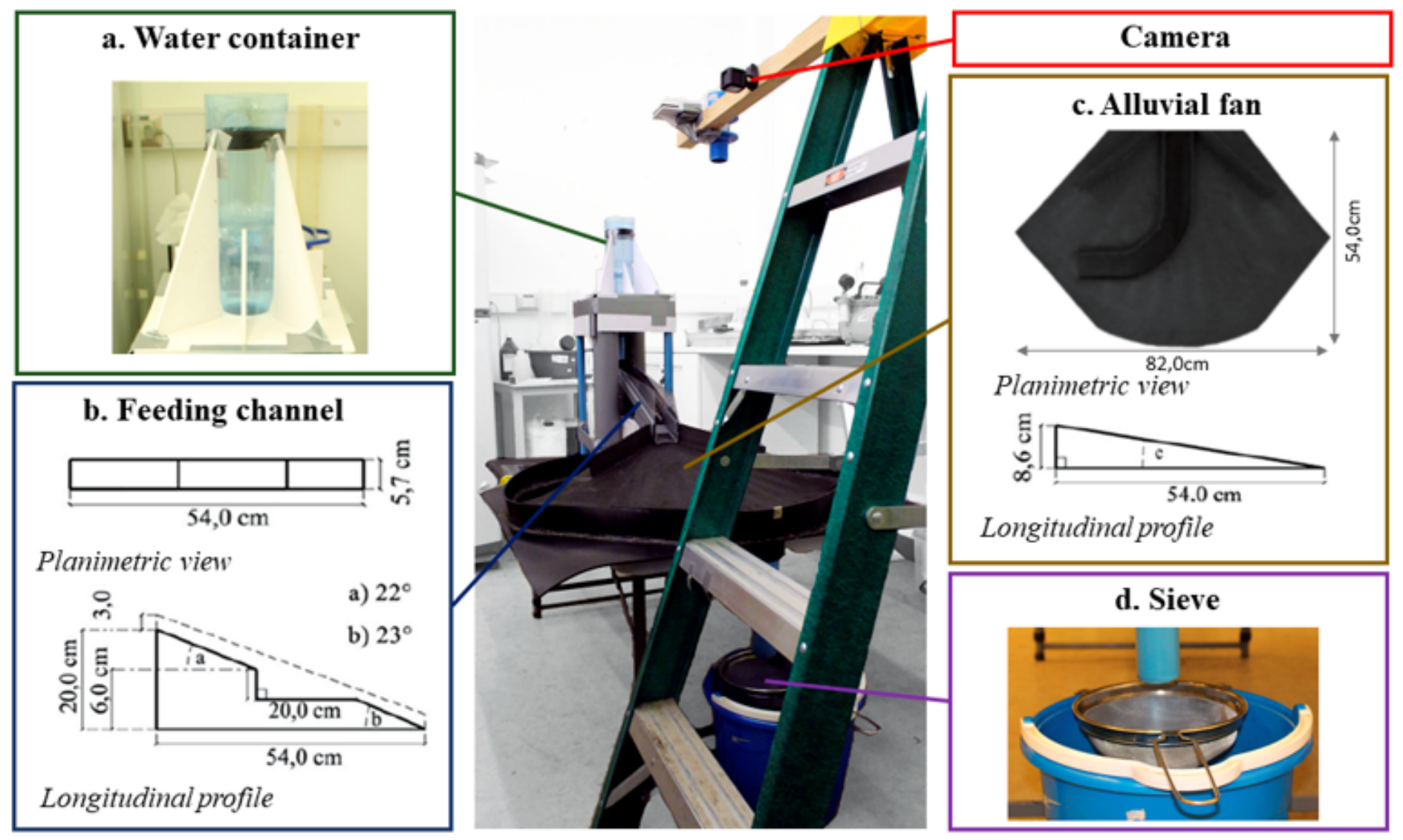

Figure 1 
Water container for water release (Panel a), Longitudinal profile of the feeding channel (Panel b), an overview of the experimental setup (central sector of the Figure), planimetric view and longitudinal profile of the alluvial fan equipped with the curved guiding channel (Panel c), Collection system (Panel d): sieve and bucket for the separated storage of water and sediment exported from the experimental system (modified after Mazzorana et al. 2020)

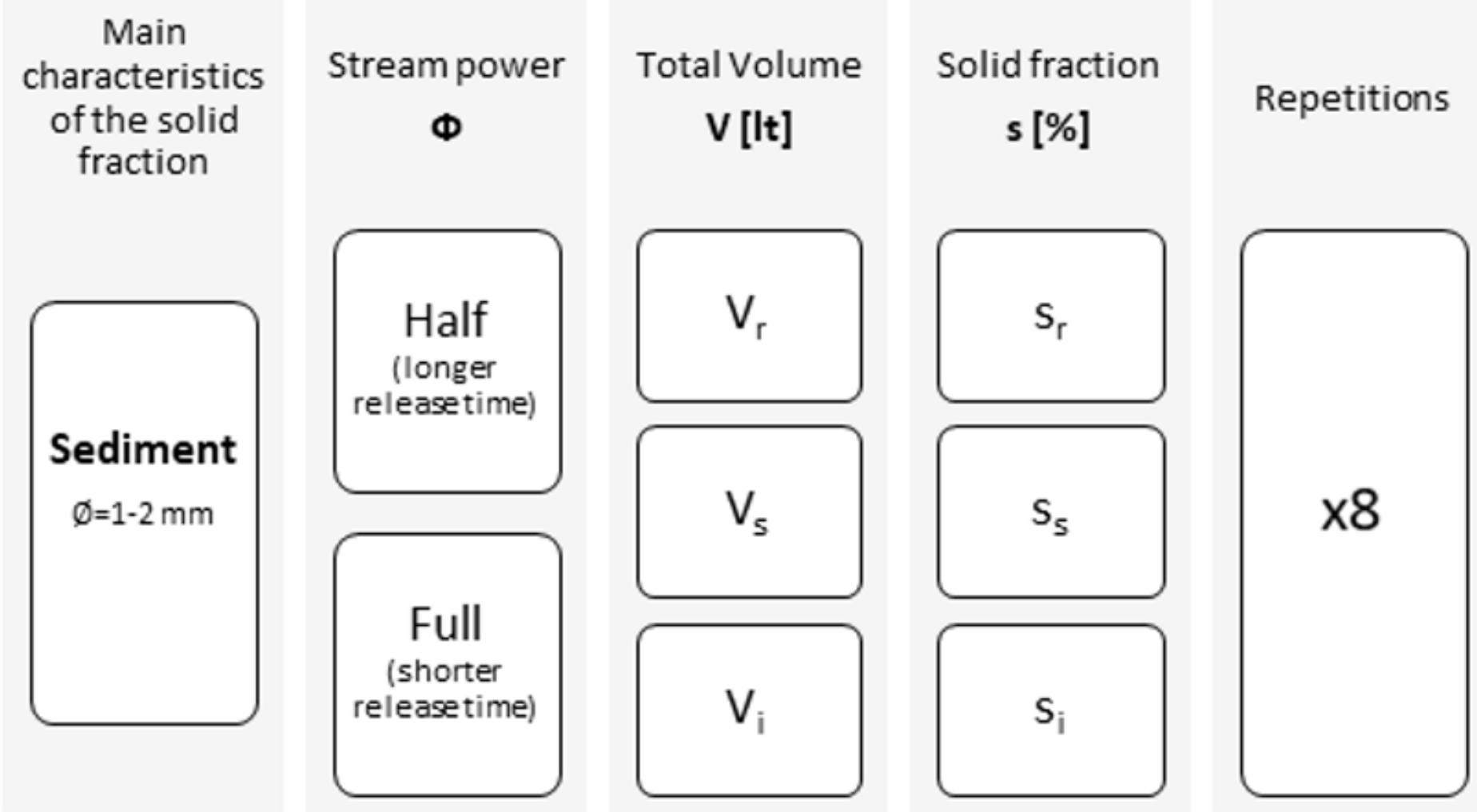

Figure 2

Scheme of the experimental program detailing the main characteristics of the solid fraction, the imposed stream power regimes $(\Phi)$, the total flow volumes $(V)$, the percentage of the solid fractions within the mixture (s) and the number of repetitions 


\section{Experimental configuration: $\Phi_{h}, V_{i}, s_{i}$}

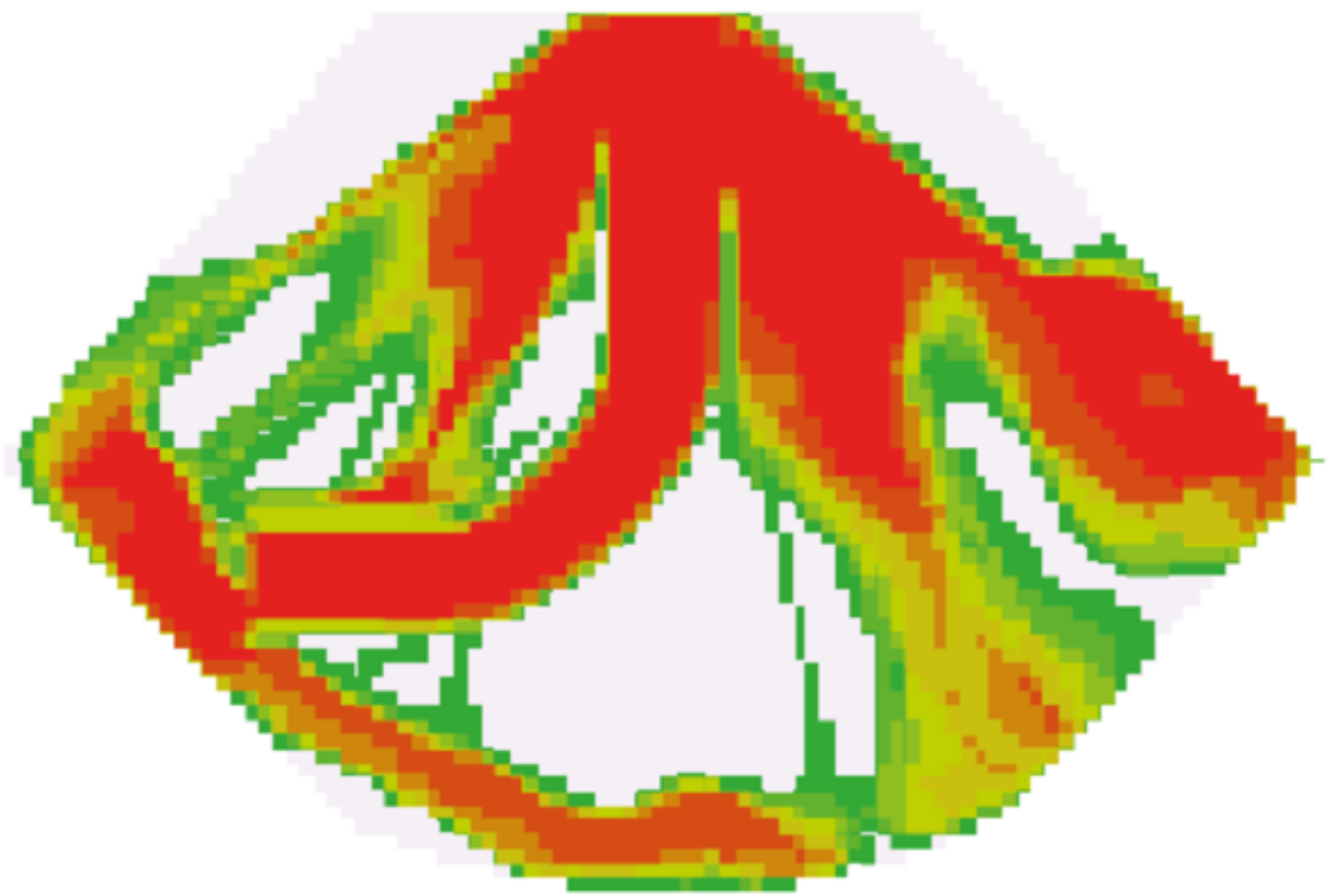

\section{Total Exposure}

Probability
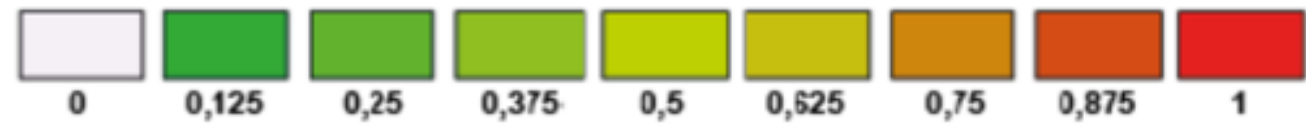

\section{Figure 3}

Probability map associated the experimental configuration (Фh, Vi, si) 


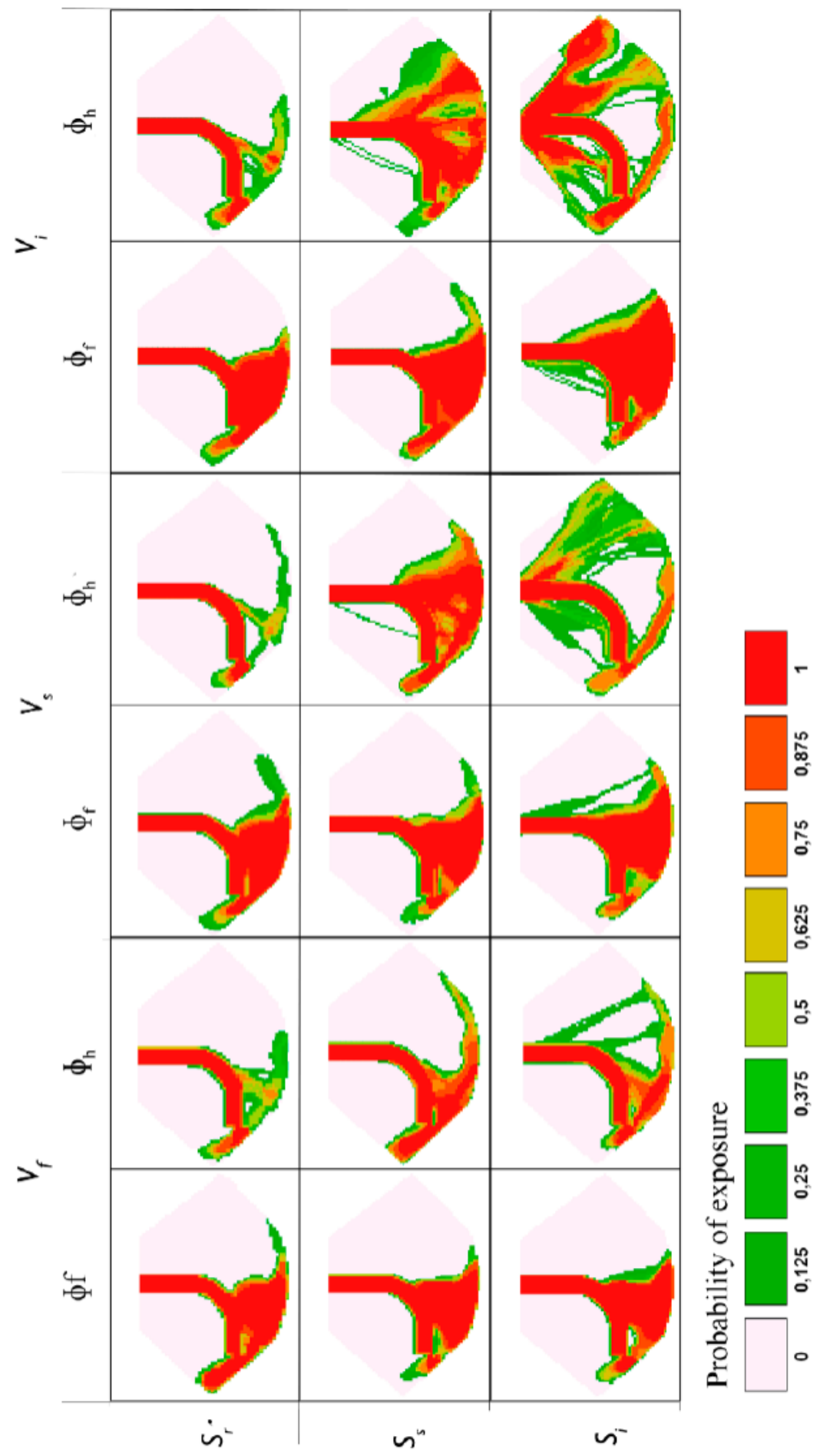

\section{Figure 4}

Total exposure probability maps associated with the entire set of experimental conditions specified in the experimental program. $\mathrm{Vr}$, Vs, Vi mean reduced, standard and increased released total volume; sr, sr, sr, indicate the reduced, standard and increased solid fraction, respectively; $\Phi f$ and $\Phi f$ symbolize the imposed stream power regimens (full and half, respectively) 


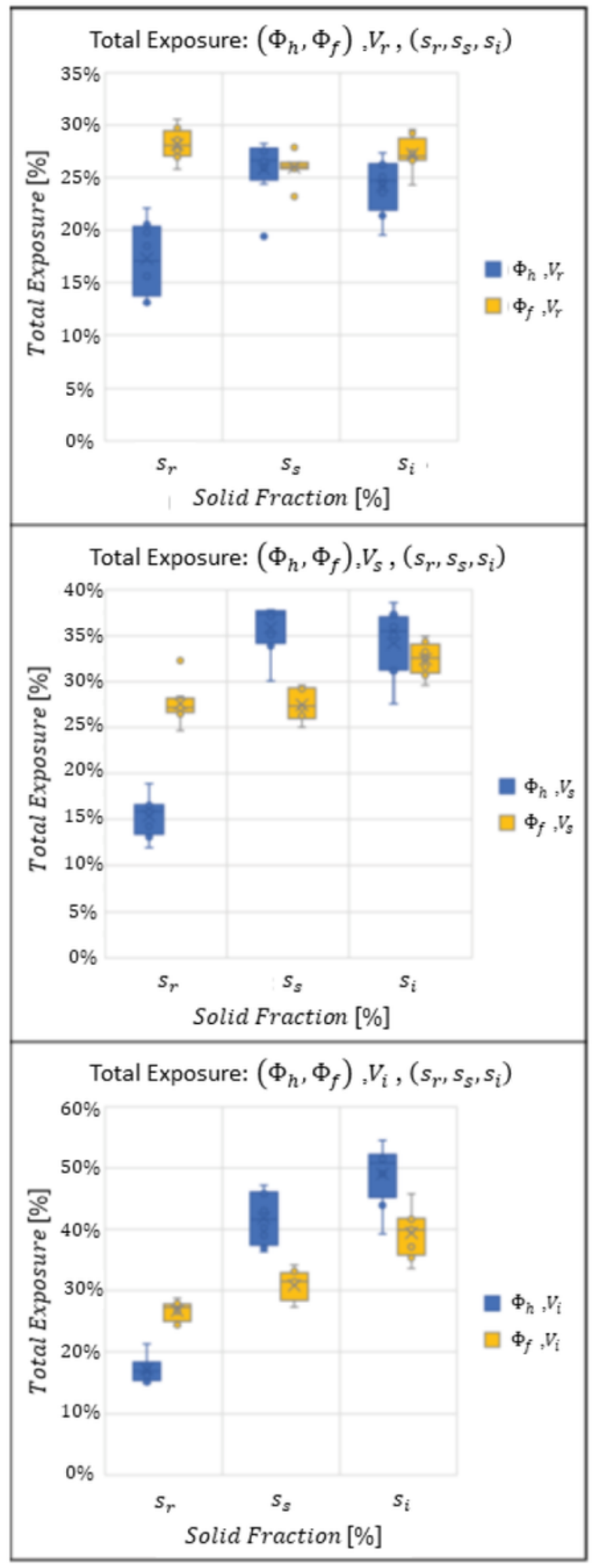

\section{Figure 5}

From top to bottom: Boxplots representing the variability (interquartile ranges) and the median of the

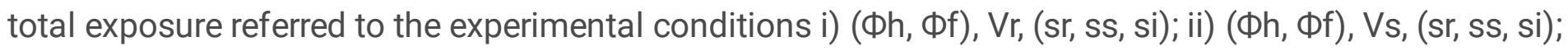
and (iii) (Фh, Фf), Vi, (sr, ss, si) 


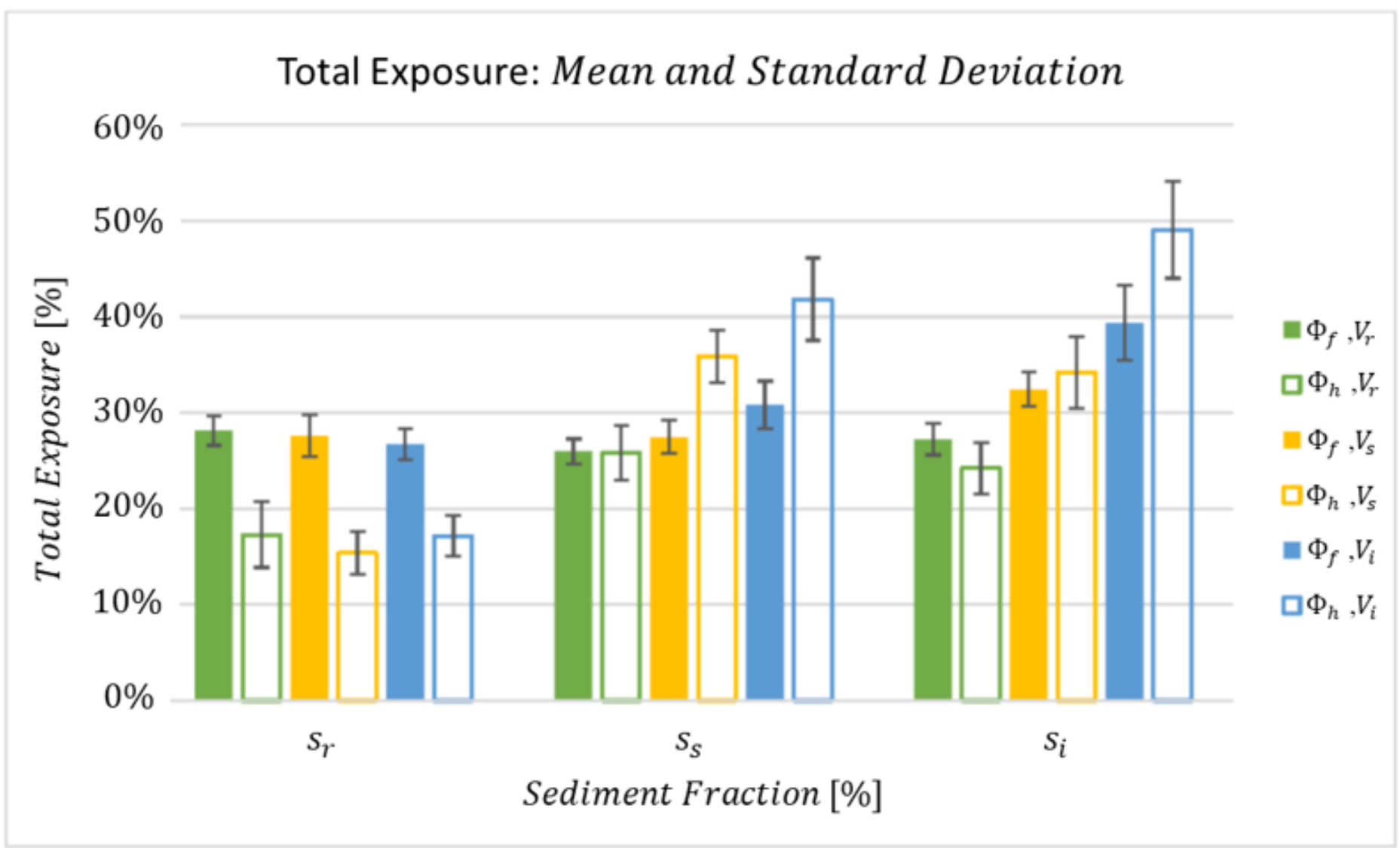

Figure 6

Bar chart with whiskers: For each experimental configuration defined through the levels of the variables, $(\Phi h, \Phi f),(V r, V s, V i)$, and (sr, ss, si), respectively, the height of the bar accounts for the mean total exposure whereas the extent of whiskers represents its standard deviation 
A)

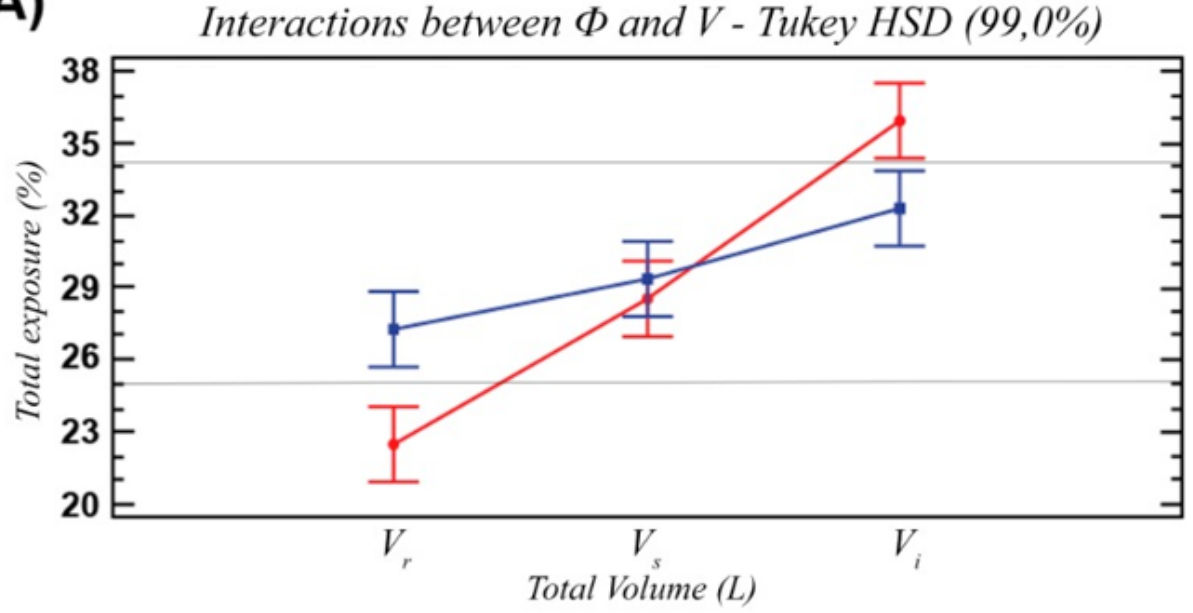

Stream power

$\longrightarrow \Phi_{f}$

B)
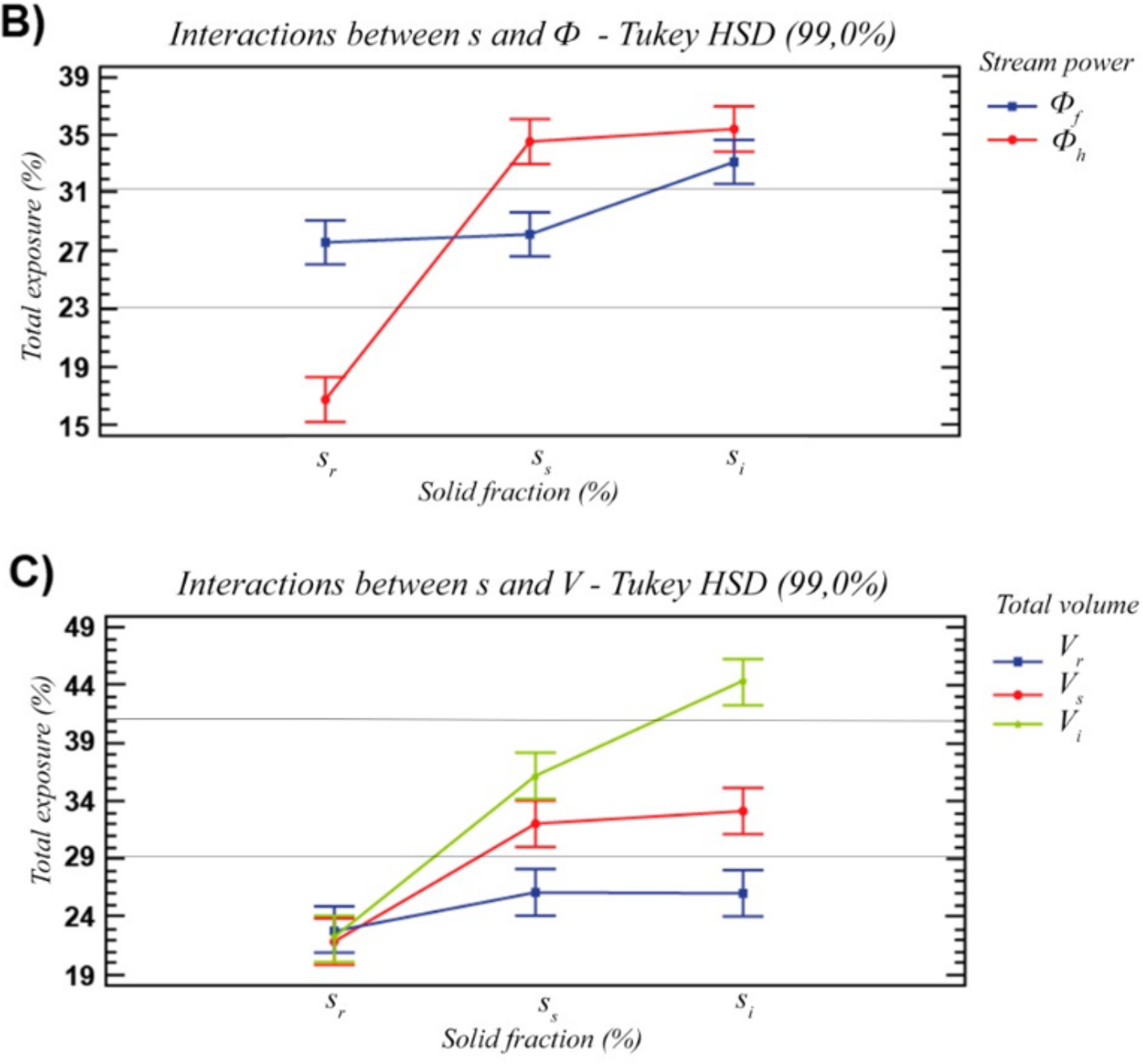

Figure 7

Interaction plots: Effects on the main response considering the interaction released total volume and applied stream power regime (Panel A), predisposed solid fraction and applied stream power (panel B), and predisposed solid fraction and released total volume (Panel C). Rectangles circumscribe groups of experimental conditions considering two factors leading to significantly different effects. 